\title{
Evaluation of Transverse Markings as a Speed Transition Zone Countermeasures in Small, Rural Communities
}

\author{
Shauna Hallmark, Neal Hawkins, Skylar Knickerbocker \\ Institute for Transportation at Iowa State University, Ames, USA \\ Email: shallmar@iastate.edu,hawkins@iastate.edu, snick@iastate.edu
}

How to cite this paper: Hallmark, S., Hawkins, N. and Knickerbocker, S. (2021) Evaluation of Transverse Markings as a Speed Transition Zone Countermeasures in Small, Rural Communities. Journal of Transportation Technologies, 11, 61-77. https://doi.org/10.4236/jtts.2021.111004

Received: December 3, 2020

Accepted: January 23, 2021

Published: January 26, 2021

Copyright $\odot 2021$ by author(s) and Scientific Research Publishing Inc. This work is licensed under the Creative Commons Attribution International License (CC BY 4.0).

http://creativecommons.org/licenses/by/4.0/

\begin{abstract}
Small rural communities located along major state or county roadways typically find most of the traffic along their main thoroughfares is pass-through rather than local traffic. Unfortunately, drivers passing through these communities often enter at high rates of speeds, which are often significantly higher than the speed limit of the local segment. Speed management in rural areas requires different considerations compared to urban areas and, within the US, rural speed management is not as advanced with little experience or guidance for agencies to draw on. This paper summarizes the results of a study that evaluated, in part, several different types of transverse pavement markings within the speed transition zones in small rural communities. Three different countermeasures were evaluated: converging chevrons, transverse lane markings, and optical speed bars.
\end{abstract}

\section{Keywords}

Community Entrance, Converging Chevrons, Optical Speed Bars, Pedestrian Safety, Speed Transitions, Traffic Calming, Traffic Safety, Speed Management

\section{Background}

\subsection{Introduction}

Speeding is a major contributing factor in 30 percent of fatal crashes nationally in the US [1]. Speeding in rural communities located along major highways is especially problematic given that drivers must transition from a major high-speed, rural roadway to a low-speed community setting. The rural roadway provides high-speed mobility outside the community, yet the same road within town pro- 
vides local access and accommodates pedestrians of all ages as well as on-street parking, bicycles, and other features unique to the character of a small rural community.

Drivers who have been traveling for some distance on the high-speed road, and are traveling through the community, may not receive the appropriate clues that the character of the roadway is changing and as a result do not adjust their speeds appropriately.

Addressing speeding issues through rural communities is particularly challenging given that small rural communities often lack the engineering expertise and resources necessary to address the persistent challenge of slowing high-speed through-traffic effectively. In addition, motor vehicle crashes injury rates are higher in rural versus urban areas due in part to increased emergency response service (EMS) times, reliance on volunteer EMS, and increased transport time to definitive care [2]. EMS response times in rural areas are 1.6 to 2 times longer than for urban areas [3] [4] and fatal injury crash rates are 2 to 3 times higher in rural than urban areas [2] [5]. Pedestrians are more than twice as likely to be killed in a pedestrian-vehicle collision in a rural area as in an urban area [6].

While speed management has been evaluated and used extensively on lower-speed urban roadways in the US, little information is available regarding the types of speed management techniques that are appropriate and effective along major highways transitioning within rural communities. Typical speed management techniques used on lower-speed roadways cannot be assumed to be portable to rural higher-speed roadways.

\subsection{Objectives and Project Scope}

Since speed management in the US has focused primarily on urban roadways, there is a lack of knowledge about which speed management strategies are appropriate for use along major routes through small rural communities. The objective of the research described in this paper was to assess the effectiveness of speed management countermeasures along major highways at the entrance to small rural communities. A variety of low-cost countermeasures were selected which the team determined were appropriate for this type of setting.

\section{Site Selection}

Sites were selected from rural Iowa communities who volunteered to participate and also met the following characteristics:

Main road through a rural community (serves as a major road into and out of the community and does not terminate within the community) with rural defined as a population less than 5000 .

Paved roadway.

Speed limit of $45 \mathrm{mph}$ or under within the community and $55 \mathrm{mph}$ or higher outside the community.

Demonstrated speeding problem or crash problem attributed to speed (de- 
termined by study team).

Volume of $500 \mathrm{vpd}$ or higher entering the community.

No unusual characteristics (i.e., presence of railroad crossing, unusual geometry).

The team visited each potential community to determine whether the evaluation conditions were met and whether speed management would be feasible. Spot speed studies were conducted to confirm whether a speeding problem existed (defined as the mean or 85th percentile speed being 5 or more mph over the posted speed limit). Three different communities were selected for the transverse markings countermeasures. Other sites were selected for other types of countermeasures but are not the focus of this paper [7] [8].

\subsection{Selection of Countermeasures}

Countermeasures were selected by compiling a list of urban speed management strategies and then assessing each to determine whether they were feasible for rural communities. Consideration was given to whether the countermeasure would pose a safety hazard for high-speed vehicles. Although speed limits along major roads within rural communities can be as low as $25 \mathrm{mph}$, the same roadway outside the community is signed at 55 or $60 \mathrm{mph}$ so drivers entering the community may be traveling at much higher speeds than the posted speed limit. As a result, countermeasures which could not be traversed by high-speed vehicles, such as a speed table, were not appropriate. Rural communities also have different traffic, roadway, and driver characteristics than urban areas. Agricultural equipment is a common fixture along rural roadways and consideration was given to whether these vehicles could negotiate a particular countermeasure. Additionally, rural drivers may be less familiar with unusual traffic control approaches and rural communities in Iowa tend toward older populations.

Rural speed management is more advanced in Europe and other countries than in the US. Consequently, countermeasures utilized in rural European communities were identified as well and considered in the context of rural conditions and norms in the US [9] [10] [11] [12] [13].

Finally, countermeasures needed to be reasonably low cost due to project constraints (less than $\$ 10,000$ USD). In addition, the countermeasures needed to conform to the Manual on Uniform Traffic Control Devices (MUTCD) or be able to receive experimental approval.

Eleven different countermeasures were selected and evaluated. Categories of countermeasures included transverse lane markings, lane narrowing, dynamic speed feedback signs, and creation of center medians, colored entrance countermeasures, and speed humps. This paper summarizes the effectiveness of several different transverse pavement markings. Transverse pavement markings usually consist of transverse bars, lines, or chevrons. These markings are perceptual countermeasures that are manipulations of the roadway visual environment designed to increase a driver's perception or feeling of speed. Ideally, this 
leads drivers to modify their speed to suit the prevailing road conditions. Perceptual countermeasures include lane-width reduction and transverse lines [14].

Pavement marking countermeasures were ideal for rural community entrances since they can be easily placed and do not physically alter the roadway. Several different types of transverse countermeasures have been reported including chevrons, optical speed bars, and transverse lines. Transverse countermeasures usually consist of a static marking with consist spacing or changing markings/spacing.

Rutley [15] suggested that placement of transverse lines with exponentially decreasing distance between progressive lines provides the illusion of increased speed or insufficient deceleration. Some markings may also decrease in size contributing to the perception. Ideally, this perception encourages drivers to be aware of their speeds and to slow down. This spacing configuration assumes that the perception of speed affects driver behavior [16].

Other researchers have suggested that a driver's perceptual system is sensitive simply to the presence or absence of stimuli rather than rate of streaming of the countermeasure [17] [18]. As a result, the mere presence of the countermeasure may be sufficient to influence speed.

Three different types of transverse markings were evaluated. Converging transverse bars were used along three different roadways entering one community. Converging chevrons were evaluated at two community entrances in another community. The third countermeasure utilized a variation of the transverse bars with consistent spacing placed in three locations within two communities. Each countermeasure is described in more detail in the results sections (Section 4).

The following summarizes known information about the effectiveness of various transverse countermeasures. Although the majority of the studies are for rural applications, most have been for curves, intersection approaches, work zones, rather than within rural communities.

\subsection{Summary of Known Effectiveness of Selected Countermeasures}

Converging Transverse Bars

Transverse bars, also referred to as optical speed bars, have been applied in various settings. Transverse bars are typically short rectangular markings placed along the edge of the roadway. Longer lines which extend across the travel lane have also been used. A converging distance between bars is frequently used with this type of transverse markings. One study was available which summarized use of the countermeasure within in a rural community. Other relevant studies are also summarized.

The Virginia DOT (VDOT) tested transverse speed bars along a major four-lane undivided roadway $(12,000$ vehicles per day $\{\operatorname{vpd}\})$ at the entrance to a small rural community. The roadway speed limit was posted at $55 \mathrm{mph}$ outside 
the community and $45 \mathrm{mph}$ within the community. An average decrease in mean speed of $3.2 \mathrm{mph}$ was reported at 1 week and $6.5 \mathrm{mph}$ at 90 days [19].

Katz [20] reported on use of converging transverse bars at sites in New York (freeway exits), Mississippi (two-lane road), and Texas (two-lane curve). Overall, a 4 -mph reduction in average speeds and a 5 -mph reduction in 85 th percentile speeds were found.

Meyer [16] evaluated use of peripheral transverse markings on a rural interstate work zone in Kansas. Three different patterns were used to maintain reductions in driver speed through the test section. The markings, which consisted of a single bar placed across the traffic lane, decreased in width (42 to 24 inches), and spacing (52 to 29 feet). Reductions in both mean and 85th percentile speeds of 1 to $2 \mathrm{mph}$ from an upstream control location to locations within the countermeasure were reported.

Martinez et al. [13] evaluated a combination countermeasure that included transverse white bars along AS-19, a two-lane paved roadway in northern Spain. The countermeasures were applied along the approaches to a high-speed intersection (about 150 feet before and after). One approach had a curve with limited sight distance and two bus stops.

Before installation of the countermeasure, due to the limited intersection sight distance, the speed limit was lowered from $90 \mathrm{~km} / \mathrm{h}(55.9 \mathrm{mph})$ to $60 \mathrm{~km} / \mathrm{h}(37.3$ $\mathrm{km} / \mathrm{h}$ ). Next, a countermeasure consisting of clusters of five bars placed progressively closer was installed. Raised pavement markers were also placed along the edge of the roadway and reflective markers were placed along the guardrail to provide further delineation. Mean and 85th percentile speeds decreased about 3 $\mathrm{mph}$ with the decreased speed limit. Mean speed decreased an additional $11 \mathrm{mph}$ and 85th percentile speed decreased another $13 \mathrm{mph}$ after the countermeasure was installed.

Latoski [21] applied optical speed bars on a tangent section of a rural, two-lane highway in Mohave County, Arizona (daytime/nighttime speed limit: $55 / 45 \mathrm{mph}$ ). The researchers placed two bars (each $24 \times 8$ inches) 8 inches apart with decreasing spacing between successive pairs of bars. A $2.0 \mathrm{mph}$ decrease in both mean and 85th percentile speed immediately after installation for all time periods was reported. At three months, mean speed had decreased by $2.2 \mathrm{mph}$ and 85th percentile speed had decreased by $3.0 \mathrm{mph}$.

Gates et al. [22] evaluated the impact of transverse bars ( $18 \times 12$ inches $)$ on a freeway curve in Wisconsin (advisory speed was $50 \mathrm{mph}$ ). The bars were placed with continuously decreasing spacing. The researchers found decreases of 1.1 to $5.0 \mathrm{mph}$ in average speeds and up to $3.0 \mathrm{mph}$ in 85 th percentile speeds one week after installation.

\section{Converging Chevrons}

Chevron patterns have been used as a speed management countermeasure is rural settings. In most applications, a decreasing chevron size and spacing have applied. No applications were found within rural communities, although several 
studies have reported their use in other settings.

A study in Minnesota used a converging chevron pattern in each travel lane as a speed management measure at an intersection approach [23]. The Minnesota project also placed $30 \mathrm{mph}$ pavement markings and added high-visibility wind spinners on speed limit signs. The roadway was a community collector street with average daily traffic (ADT) of 4000.

Data were collected before and at 1 week and 2 years after installation. Reductions of 4 and $6 \mathrm{mph}$ in mean speed and 85th percentile speeds, respectively, were noted 1 week after installation. A decrease of $2 \mathrm{mph}$ in both mean and 85th percentile speeds resulted at 2 years after installation. The markings were re-painted after four years, because the researchers felt that the fading paint had an impact on the results. After re-painting, the researchers found similar speed-reduction results as those conducted 1 week after initial installation [23].

Voigt and Kuchangi [24] evaluated use of converging chevrons on a freeway-to-freeway ramp connector in El Paso, Texas. The site had approximately $18,000 \mathrm{vpd}$ with 2 percent heavy trucks. The posted advisory speed was $30 \mathrm{mph}$. The average decrease in mean speed was $0.3 \mathrm{mph}$ at 1 month after installation and the average reduction in 85th percentile speed was $0.5 \mathrm{mph}$.

Drakapoulos and Vergou [25] evaluated the effect of on-pavement chevrons on a freeway-to-freeway connector in Wisconsin. Sixteen chevrons were placed at decreasing distances over 610 feet. Data were collected before and at 20 months after installation. The researchers found a mean speed reduction of 15 $\mathrm{mph}$ and a $17-\mathrm{mph}$ reduction in 85 th percentile speed.

Hunter et al. [26] evaluated the effectiveness of converging chevrons on two-lane freeway-to-freeway directional ramps in Atlanta, Georgia. Data were collected before installation of the countermeasure and at a several periods after. A decrease in mean and 85th percentile speeds of about $2 \mathrm{mph}$ resulted at 1 month and about $1 \mathrm{mph}$ for 9 months after installation.

\section{Equidistant Transverse Markings}

Several studies have utilized transverse lines or bars with equidistant spacing rather than using decreasing spacing between successive lines. Two studies were available where the countermeasure was applied at rural intersection approaches.

Godley et al. [18] evaluated converging and fixed distance transverse lines in a simulator study (with 24 participants) at approaches to rural intersections in Australia. The speed limit for the test roads was $62.1 \mathrm{mph}(100 \mathrm{kph})$. Three countermeasures were evaluated: 1) full-lane-width transverse lines with successive lines placed at exponentially decreasing distance; 2) full-lane-width transverse lines with equidistant spacing; and 3) transverse bars with successive bars placed at exponentially decreasing distance. A control intersection with no countermeasure was also present.

Speeds were collected at various locations through the countermeasure and compared to similar locations at the control intersection. Data were compared 
for 200 and 300 meters (about 218 and 328 yards or about 656 and 984 feet) upstream of the intersection. The full-lane peripheral and full-lane fixed lines were within $0.6 \mathrm{mph}$ at all data collection locations and were combined by Godley et al. [18] for comparison. The full-lane width line countermeasures were $6.2 \mathrm{mph}$ lower than for the control intersection at 300 meters upstream and $5.0 \mathrm{mph}$ lower at 200 meters. The peripheral bars were $4.3 \mathrm{mph}$ lower at 300 meters upstream and $6.2 \mathrm{mph}$ lower at 200 meters.

Ray et al. [27] evaluated transverse speed markings (five sets of transverse bars with dimensions of 12 inches by 8 inches spaced 15 feet apart) at the approaches to four high-speed intersections. The markings were placed on both sides of the travel lane in the direction of the intersection. The mean speed reduction was 0.6 mph overall and $0.9 \mathrm{mph}$ for 85 th percentile speeds.

\subsection{Countermeasure Application}

After countermeasures were selected, the team consulted the Manual on Uniform Traffic Control Devices (MUTCD) and if necessary requested approval for use of an individual countermeasures. The MUTCD is a compilation of national US standards for traffic control devices. Optical speed bars, one type of transverse bars, are covered in Section 3B of the MUTCD [28]. Experimental approval was requested from and granted by the Federal Highway Administration (FHWA) Office of Transportation Operations MUTCD team for the converging chevron and equidistant transverse bar countermeasure.

A description of the individual countermeasures is described in the following results section. After conducting a before speed analysis, the team worked with the corresponding agency and installed the countermeasures. Speed data were then collected after installation. In most cases the countermeasure was placed upstream to terminate at the community entrance.

\section{Methodology}

Change in speed metrics were the measures of effectiveness utilized. There were not a sufficient number of sites for a crash analysis.

Pneumatic road tubes (JAMAR FLEX HS counters) were used to collect speed data. Pneumatic road tubes are fairly accurate (99 percent accuracy for individual vehicle speeds), can collect individual vehicle data (speed, volume, headway, and classification), and are fairly low-cost.

Road tubes were typically laid just downstream of or at the countermeasure. Data were usually collected for 48 hours on a Monday through Friday avoiding holidays to avoid any unusual traffic patterns. In a few cases, due to issues with the traffic counters, data were available for only a 24-hour period. Use of full 24-hour periods avoids biasing the speed sample to speed based on time of day. .

Data were collected before installation of the countermeasures and at several after periods as described in the results section. When possible, data were collected 12 months after installation to determine whether drivers became habi- 
tuated to the countermeasures.

After data were collected, the data were checked for errors (i.e., equipment malfunction) and, if necessary, data were recollected. In some cases, the counters are not able to reconcile axle strikes to calculate speed and zero-value results. If these made up more than 10 percent of the sample, data were recollected. Otherwise, null values were removed from the dataset.

The most common statistics used in speed analyses are mean and 85th percentile speeds. A number of studies have also reported change in the number of drivers traveling a certain threshold over the posted or advisory speed. For instance, the fraction of drivers in the sample traveling 10 or more mph over the posted speed limit before installation of the countermeasure is compared with the fraction traveling 10 or more mph over after the countermeasure is installed. This metric may be more meaningful than mean or 85 th percentile speeds because it reflects reduction in high-end speeding and not only average changes in speed.

The percent change between the fraction of vehicles exceeding the posted speed before and after installation of the pavement countermeasures was calculated using Equation (1):

$$
C_{p}=\left\{\mathrm{FR}_{(\text {after }, x)}-\mathrm{FR}_{(\text {before }, x, i)}\right\} \div \mathrm{FR}_{(\text {before }, x)}
$$

where:

$\mathrm{FR}_{(\text {before, } x)}=$ fraction of vehicles exceeding posted or advisory speed by $x$ mph before installation.

$\mathrm{FR}_{(\mathrm{after}, X, i)}=$ fraction of vehicles exceeding posted or advisory speed by $x \mathrm{mph}$ after installation.

$C_{p}=$ percent change.

\section{Description of Countermeasures and Results}

Three different transverse countermeasures were evaluated. Two were variations of transverse bars. The third was a converging chevron pattern. A description of each countermeasure and the results of the speed analyses are presented in the following subsections.

\subsection{Converging Transverse Speed Bars}

Transverse speed bars (also referred to as optical speed bars) were placed at the north (State Highway/SH 215), south (County Road/CR S-62), and west (CR D-65) entrances to Union, Iowa. No countermeasure was used at the east community entrance given that a railroad track acts as a de facto speed hump at that entrance. The posted speed limit was $25 \mathrm{mph}$ at the west and south entrances and $30 \mathrm{mph}$ at the north entrance.

The optical speed bars (painted using pavement marking paint and a template) measured approximately 18 by 12 inches and were placed at decreasing distances apart as drivers traversed the countermeasure toward the community entrance as shown in Figure 1. 


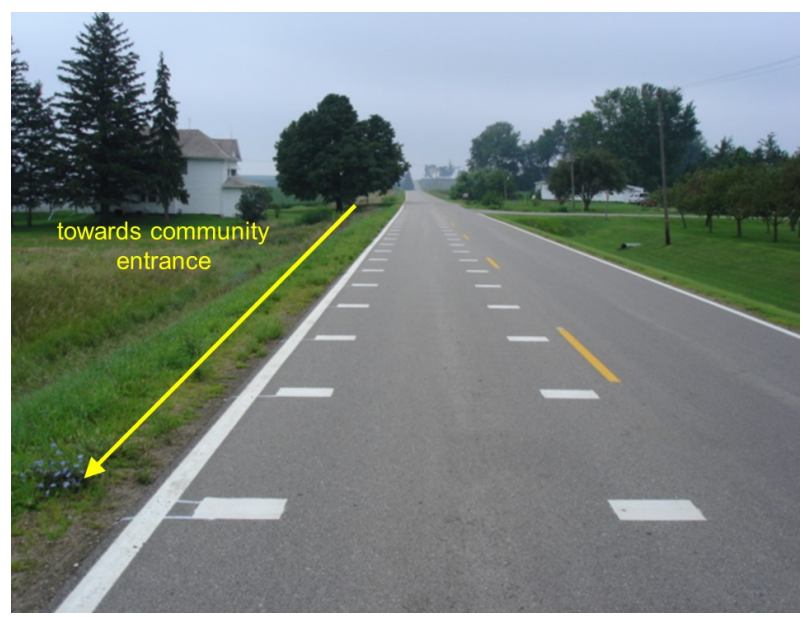

Figure 1. Optical speed bars at community entrance.

The spacing was based on the required decrease from the upstream speed transition zone to the speed limit within the community. The countermeasure was oriented so that the last set of optical bars was placed at the speed limit sign at the community entrance. Results are not presented for the 12-month after period since speed feedback signs were installed at the north and west location. Data are provided for the south community entrance where speeds were collected at 12-months.

Results of the speed analyses are shown in Table 1 and Table 2. Volume did not change significantly from the before to after periods. As indicated in Table 1 and Table 2, one site showed essentially no change in mean or 85th percentile speeds while the other two sites had decreases of up to $2 \mathrm{mph}$. As noted none of speed changes for the south community entrance were statistically significant for the 12-month after period.

The fraction of vehicles exceeding the posted speed limit by 10 or more mph decreased by 2 to 5 percent as noted in Table 2. The percentage of vehicles traveling 15 or more mph over the posted speed limit decreased by 4 to 16 percent. However, none of the changes were statistically significant.

\subsection{Equidistant Transverse Bar Pattern}

The second countermeasure consisted of a set of three transverse bars (preformed pre-cut thermoplastic) placed across the lane entering each community as shown in Figure 2.

The countermeasure was installed at three entrances to two different communities. One set was placed at the west community entrance (CR C-57) to Hazelton, Iowa ( $25 \mathrm{mph}$ posted speed limit) and the other two were installed at the north and south community entrances (CR W-40) to Quasqueton, Iowa (35 and $25 \mathrm{mph}$ posted speed limits, respectively).

The three bars across in each pattern set were spaced so that drivers can position their vehicle wheel paths between the markings. The first set of bars were placed approximately 100 feet before the first posted speed limit into the rural 
community and the bars were equidistant (about 10 feet) apart. The countermeasure was placed so that the last set of bars terminated at the first speed limit sign at the community entrance.

Table 1. Speed results for optical speed bars.

\begin{tabular}{|c|c|c|c|c|c|c|}
\hline \multirow{2}{*}{ Site } & \multirow{2}{*}{$\begin{array}{c}\text { Volume } \\
\text { (vpd) }\end{array}$} & \multicolumn{5}{|c|}{ Mean Speed (mph) } \\
\hline & & Before & $1 \mathrm{Mo}$. & Change & $12 \mathrm{Mo}$. & Change \\
\hline Union North & 1870 & 33.8 & 33.9 & $0.1(\mathrm{p}=0.67)$ & & NA \\
\hline Union South & 886 & 37.8 & 37.0 & $-0.8(\mathrm{p}=0.03)$ & 37.4 & $0.4(\mathrm{p}=0.16)$ \\
\hline \multirow[t]{2}{*}{ Union West } & 893 & 43.9 & 42.9 & $-1.0(\mathrm{p}=0.08)$ & & NA \\
\hline & & \multicolumn{5}{|c|}{ 85th Percentile Speed (mph) } \\
\hline Union North & & 41 & 41 & 0 & & NA \\
\hline Union South & & 46 & 45 & -1 & 45 & 1 \\
\hline Union West & & 53 & 51 & -2 & & NA \\
\hline
\end{tabular}

Table 2. Fraction of vehicles exceeding posted speed limit for optical speed bars.

\begin{tabular}{cccccc}
\hline \multirow{2}{*}{ Site } & \multicolumn{5}{c}{$\geq 10 \mathrm{mph}$} \\
\cline { 2 - 5 } & Before & 1 Mo. & Change & 12 Mo. & Change \\
\hline Union North & 0.21 & 0.20 & $-4.76 \%(\mathrm{p}=0.17)$ & \\
Union South & 0.70 & 0.66 & $-5.71 \%(\mathrm{p}=0.05)$ & 0.67 & $-0.46 \%(\mathrm{p}=0.05)$ \\
Union West & 0.87 & 0.85 & $-2.30 \%(\mathrm{p}=0.28)$ & \\
\hline & & & & & \\
\hline Union North & 0.06 & 0.05 & $-16.67 \%(\mathrm{p}=0.17)$ & \\
Union South & 0.45 & 0.43 & $-4.44 \%(\mathrm{p}=0.14)$ & 0.431 \\
Union West & 0.72 & 0.69 & $-4.17 \%(\mathrm{p}=0.15)$ & \\
\hline
\end{tabular}

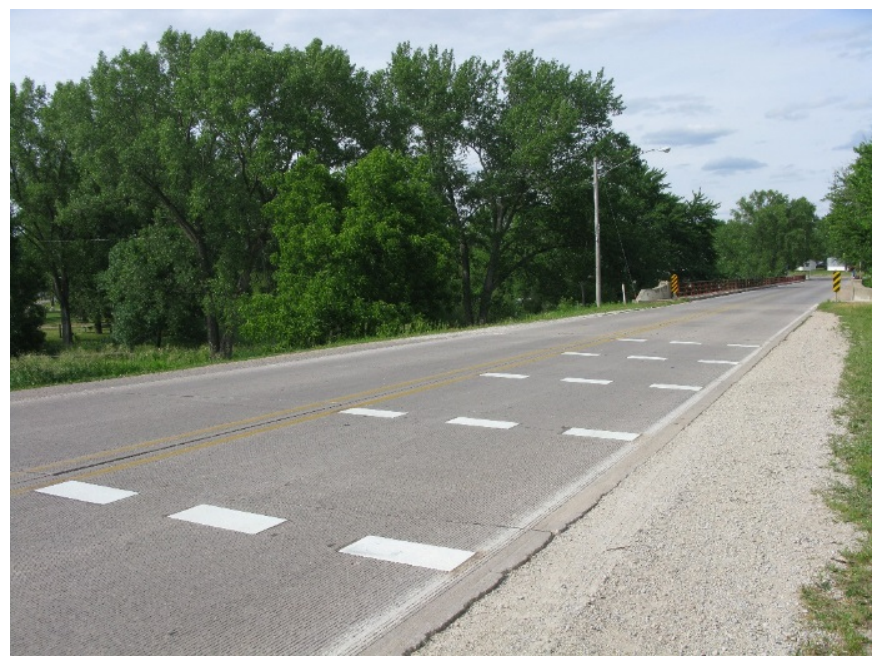

Figure 2. Transverse bars at community entrance. 
Changes in mean and 85th percentile speeds are shown in Table 3.

Mean speeds decreased at two sites (by up to $1.6 \mathrm{mph}$ for 1 month after and by up to $2.3 \mathrm{mph}$ at 12 months after installation). At the third site, speeds increased by 1.4 and $0.2 \mathrm{mph}$ for the 1 and 12 month after periods, respectively.

Similarly, 85th percentile speeds decreased at two sites by up to $1 \mathrm{mph}$ at 1 month after installation and up to $2 \mathrm{mph}$ at 12 months after installation. At the third site, 85th percentile speed increased by $2 \mathrm{mph}$ at $1 \mathrm{month}$ and $1 \mathrm{mph}$ at 12 months after installation. Although speed decreases were moderate, the reductions were sustained over time.

Changes in the fraction of vehicles exceeding the posted speed limit are shown in Table 4.

The fraction of vehicles traveling 10 or more mph over the posted speed limit decreased by about 12 percent at two sites at 1 month and by 12 and 24 percent at 12 months after installation. Increases of 24 percent at 1 month after and 3 percent at 12 months after installation were noted at the Quasqueton North location.

Table 3. Speed results for equidistant transverse bars.

\begin{tabular}{ccccccc}
\hline \multirow{2}{*}{ Site } & \multirow{2}{*}{$\begin{array}{c}\text { Volume } \\
\text { (vpd) }\end{array}$} & \multicolumn{5}{c}{ Mean Speed (mph) } \\
\cline { 3 - 7 } & & Before & $\mathbf{1}$ Mo. & Change & $\mathbf{1 2}$ Mo. & Change \\
\hline Hazelton East & 843 & 36.2 & 34.6 & $-1.6(\mathrm{p} \ll 0)$ & 34.8 & $-1.6(\mathrm{p} \ll 0)$ \\
Quasqueton North & 1868 & 41.6 & 43.0 & $1.4(\mathrm{p}=0.35)$ & 41.8 & $0.2(\mathrm{p}=0.45)$ \\
Quasqueton South & 1947 & 34.7 & 33.5 & $-1.2(\mathrm{p} \ll 0)$ & 32.4 & $-2.3(\mathrm{p} \ll 0)$ \\
\hline & & & & $\mathbf{8 5 t h}$ Percentile Speed (mph) & \\
\hline Hazelton East & & 43 & 42 & -1 & 42 & -1 \\
Quasqueton North & & 48 & 50 & 2 & 49 & 1 \\
Quasqueton South & & 41 & 40 & -1 & 39 & -2 \\
\hline
\end{tabular}

Table 4. Fraction of vehicles exceeding posted speed limit for equidistant transverse speed bars.

\begin{tabular}{cccccc}
\hline \multirow{2}{*}{ Site } & \multicolumn{5}{c}{$\geq 10 \mathrm{mph}$} \\
\cline { 2 - 6 } & Before & 1 Mo. & Change & 12 Mo. & Change \\
\hline Hazelton East & 0.59 & 0.52 & $-11.9 \%(\mathrm{p} \ll 0)$ & 0.52 & $-11.9 \%(\mathrm{p} \ll 0)$ \\
Quasqueton North & 0.37 & 0.46 & $24.3 \%(\mathrm{p} \ll 0)$ & 0.38 & $2.7 \%(\mathrm{p} \ll 0)$ \\
Quasqueton South & 0.57 & 0.5 & $-12.3 \%(\mathrm{p} \ll 0)$ & 0.43 & $-24.6 \%(\mathrm{p} \ll 0)$ \\
\hline Hazelton East & 0.32 & 0.24 & $-25.0 \%(\mathrm{p} \ll 0)$ & 0.27 & $-15.6 \%(\mathrm{p} \ll 0)$ \\
Quasqueton North & 0.11 & 0.15 & $36.4 \%(\mathrm{p} \ll 0)$ & 0.13 & $18.2 \%(\mathrm{p} \ll 0)$ \\
Quasqueton South & 0.24 & 0.2 & $-16.7 \%(\mathrm{p} \ll 0)$ & 0.11 & $-54.2 \%(\mathrm{p} \ll 0)$ \\
\hline
\end{tabular}


Similar results were found for the fraction of vehicles traveling 15 or more $\mathrm{mph}$ over the posted speed limit. Decreases of 17 to 25 percent at 1 month and 16 to 54 percent resulted at 12 months for two sites, while increases were noted at the third site (increase of 36 and 18 percent at 1 and 12 months after, respectively).

As noted, the speed reductions were maintained and even improved 12 months after installation. This result indicates the countermeasure was not losing its effectiveness over time. In addition, while the decreases in mean and 85th percentile speeds were moderate at two of the sites, the reductions in vehicles traveling 10 or $15 \mathrm{mph}$ over the posted speed limits was significant.

\subsection{Converging Chevrons}

Converging chevrons were used at the east and west community entrances (CR E-18) to Roland, Iowa (painted using standard pavement marking paint and a template) as shown in Figure 3.

The chevrons decreased in spacing and width as drivers crossed them entering the community. The spacing was based on a $10-\mathrm{mph}$ speed reduction from an initial speed of $35 \mathrm{mph}$ to the posted speed limit of $25 \mathrm{mph}$ at both entrances.

Results for mean and 85th percentile speeds are shown in Table 5.

As shown, in most cases mean and 85th percentile speeds decreased by about $1 \mathrm{mph}$ except for the 12 month after period at the east entrance where 85th percentile speeds decreased by $4 \mathrm{mph}$.

Results for changes in drivers traveling over the posted speed limit are provided in Table 6.

Table 5. Speed results for converging chevron at entrance to small rural community.

\begin{tabular}{|c|c|c|c|c|c|c|}
\hline \multirow{2}{*}{ Site } & \multirow{2}{*}{$\begin{array}{l}\text { Volume } \\
\text { (vpd) }\end{array}$} & \multicolumn{5}{|c|}{ Mean Speed (mph) } \\
\hline & & Before & $1 \mathrm{Mo}$ & Change & $12 \mathrm{Mo}$ & Change \\
\hline Roland East & 2200 & 29.6 & 29.2 & $-0.4(\mathrm{p}=0.03)$ & 28.4 & $-1.2(\mathrm{p} \ll 0)$ \\
\hline \multirow[t]{2}{*}{ Roland West } & 2420 & 30.8 & 29.7 & $-1.1(\mathrm{p} \ll 0)$ & 29.6 & $-1.2(\mathrm{p} \ll 0)$ \\
\hline & & \multicolumn{5}{|c|}{ 85th Percentile Speed (mph) } \\
\hline Roland East & & 36 & 35 & -1 & 32 & -4 \\
\hline Roland West & & 35 & 34 & -1 & 34 & -1 \\
\hline
\end{tabular}

Table 6. Speed results for converging chevrons at entrance to small rural community.

\begin{tabular}{cccccc}
\hline \multirow{2}{*}{ Site } & \multicolumn{5}{c}{$\geq 10 \mathrm{mph}$} \\
\cline { 2 - 6 } & Before & $\mathbf{1 ~ M o . ~}$ & Change & $\mathbf{1 2}$ Mo. & Change \\
\hline Roland East & 0.20 & 0.17 & $-15.0 \%(\mathrm{p}<0.01)$ & 0.06 & $-70.0 \%(\mathrm{p} \ll 0)$ \\
Roland West & 0.21 & 0.14 & $-33.3 \%(\mathrm{p} \ll 0)$ & 0.14 & $-33.3 \%(\mathrm{p} \ll 0)$ \\
\hline & & \multicolumn{5}{c}{$\geq \mathbf{1 5} \mathrm{mph}$} & & $-92.0 \%(\mathrm{p} \ll 0)$ \\
\hline Roland East & 0.05 & 0.04 & $-20.0 \%(\mathrm{p}=0.14)$ & 0.004 & $-33.3 \%(\mathrm{p} \ll 0)$ \\
\hline Roland West & 0.03 & 0.025 & $-16.7 \%(\mathrm{p}=0.09)$ & 0.02 & \\
\hline
\end{tabular}



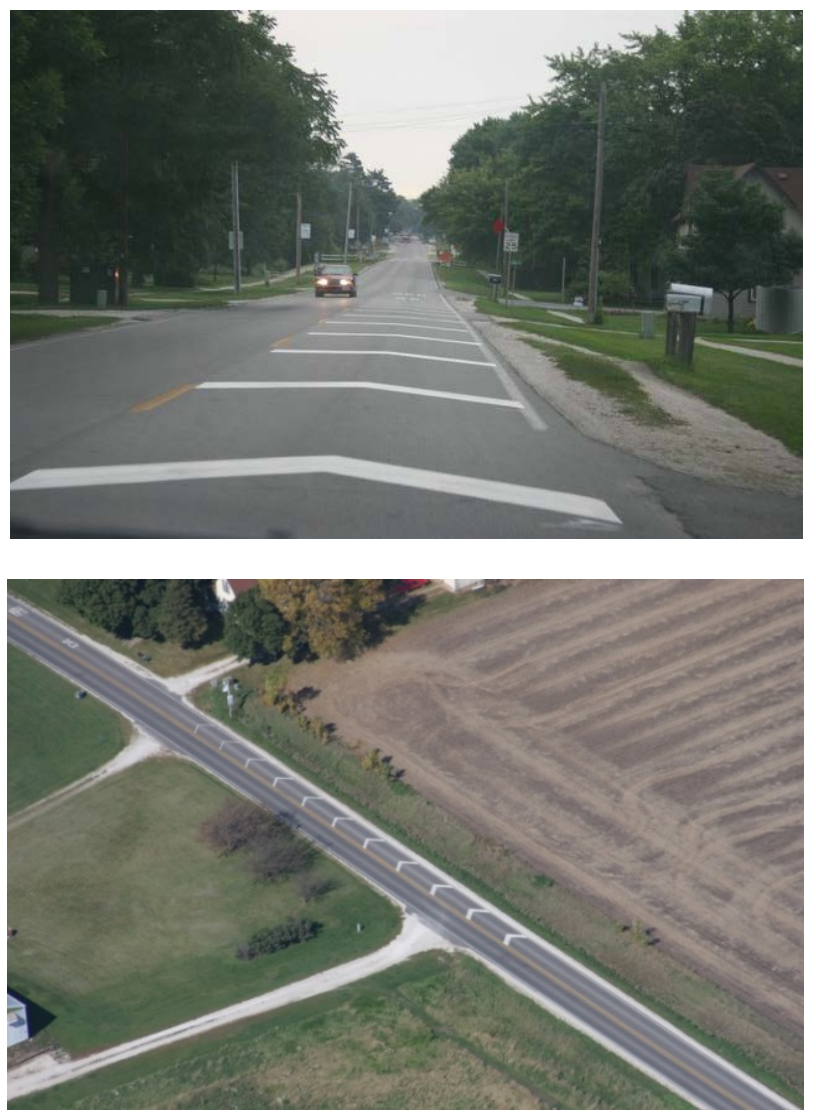

Figure 3. Converging chevrons at community entrance.

As indicated, the fraction of vehicles traveling 10 or more mph over the posted speed limit decreased by 15 and 33 percent at 1 month and 70 and 33 percent at 12 months. The fraction of vehicles traveling 15 or more mph over the posted speed limit decreased by 20 and 16 percent at 1 month and 33 and 92 percent at 12 months.

As shown, speed reductions were sustained over time. In addition, while the changes in mean and 85th percentile speeds were moderate, significant decreases in vehicles traveling 10 to $15 \mathrm{mph}$ over the posted speed limit were observed.

\section{Summary}

\subsection{Discussion}

Speeding is a persistent safety issue for communities. The problem is exacerbated for small rural communities particularly when they are located along major state or county highways and, as a result, much of the traffic along their main thoroughfares is pass-through rather than local traffic. The challenge is a significant issue given that crashes in rural areas are more likely to result in severe outcomes due to increased emergency response times.

Speed management in rural areas requires different considerations than for urban areas and, within the US, rural speed management is in its infancy with little experience or guidance for agencies to draw on. 
This paper summarizes results of a study that evaluated a use of three types of transverse pavement markings applied within the speed transition zone in small rural communities in Iowa.

Converging chevrons were one transverse countermeasure tested. The chevrons were applied at the east and west entrances to one rural community along a county highway. The chevrons decreased in size and spacing as drivers entering the community passed over the countermeasure. Mean speeds decreased by about $1 \mathrm{mph}$ for both the 1- and 12-month periods after installation of the countermeasure. Decreases of $1 \mathrm{mph}$ in 85th percentile speed occurred at 1 month for both locations and up to $4 \mathrm{mph}$ at 12 months. There were also significant decreases in the fraction of vehicles traveling 10 or more and 15 or more $\mathrm{mph}$ over the posted speed limit. Decreases of up to 69 percent in the fraction of vehicles traveling 10 or more mph over and up to 93 percent in the fraction of vehicles traveling 15 or more mph over were observed.

Transverse converging speed bars were evaluated at the south, west, and north entrances of another community. The roadways were state and county highways outside the community. The speed bars were placed in pairs on both sides of the lane. The countermeasure size was constant but the distance between sets of bars decreased as drivers progressed into the community. Data were collected 1 month after the countermeasure was installed. Mean speeds decreased by about $1 \mathrm{mph}$ and 85th percentile speeds decreased by up to $2 \mathrm{mph}$. There were decreases in the fraction of vehicles traveling 10 or more and 15 or more mph over the posted speed limit, but most of the changes were not statistically significant.

The third countermeasure was a pattern of three transverse bars placed with equidistant spacing. The countermeasure was placed at the north and south entrances to one community along a county highway and at the east entrance to another community, also along a county highway. Two of the three sites where transverse equidistant bars were applied had moderate decreases in mean and 85th percentile speeds and significant decreases in the fraction of vehicles traveling 10 or $15 \mathrm{mph}$ over the posted speed limit. One site had increases in all speed metrics. It was unknown why speeds increased at the one location. However, it is unlikely that the countermeasure caused drivers to increase their speeds. Although data were collected for several days before the countermeasure and data were checked for obvious errors, it is possible that speeds in the before period were artificially low due to some unknown factors.

\subsection{Conclusions}

Overall, these transverse countermeasures were moderately effective in reducing mean and 85th percentile speeds. In many cases, the countermeasures were very successful in reducing the fraction of drivers who were traveling more than 10 or $15 \mathrm{mph}$ over the posted speed limit. In addition, the countermeasures appeared to maintain their effectiveness over time.

Transverse countermeasures are reasonably low cost and can be applied easily. The optical speed bars and converging chevrons were both applied using pave- 
ment marking paint and templates. Wear was an issue and, as a result, the equidistant transverse countermeasure was applied using a thermoplastic product. Although higher in cost, need for maintenance was decreased. In all cases, skid resistance of the countermeasures should be ensured.

\subsection{Practical Applications}

Addressing speeding issues through rural communities is particularly challenging given that small rural communities often lack the engineering expertise and resources necessary to address the persistent challenge of slowing high-speed through-traffic effectively. Rural communities that find it difficult to slow through-traffic may use these findings to help mitigate this critical safety issue cost-effectively. Slowing speeding vehicles may encourage pedestrian activities, such as walking and bicycling and also improve community interaction and vitality.

\section{Acknowledgements}

The team would like to thank the Iowa Department of Transportation, the Iowa Highway Research Board, the Midwest Transportation Consortium, and the Federal Highway Administration for funding this study. We would like to thank the Iowa cities of Hazleton, Jesup, Ossian, Quasqueton, Rowley, and St. Charles for participating in the study. We would especially like to thank Brian Keierleber, the county engineer for Buchanan County, Iowa for his field assistance and enthusiastic support.

\section{Conflicts of Interest}

The authors declare no conflicts of interest regarding the publication of this paper.

\section{References}

[1] National Highway Traffic Safety Administration (NHTSA) (2011) Traffic Safety Facts: 2011 Data. Speeding. DOT HS 811 751. NHTSA, Washington DC.

[2] Zwerling, C., Peek-Asa, C., Whitten, P.S., Choi, S.-W., Sprince, N.L. and Jones, M.P. (2005) Fatal Motor Vehicle Crashes in Rural and Urban Areas: Decomposing Rates into Contributing Factors. Injury Prevention, 11, 24-28. https://doi.org/10.1136/ip.2004.005959

[3] Gonzalez, R.P., Cummings, G.R., Phelan, H.A., Mulekar, M.S. and Rodning, C.B. (2009) Does Increased Emergency Medical Services Prehospital Time Affect Patient Mortality in Rural Motor Vehicle Crashes? A Statewide Analysis. The American Journal of Surgery, 197, 30-34. https://doi.org/10.1016/j.amjsurg.2007.11.018

[4] National Highway Traffic Safety Administration (NHTSA) (2006) Traffic Crashes Take their Toll on America's Rural Roads. DOT-HS-810-658. NHTSA, Washington DC.

[5] National Highway Traffic Safety Administration (NHTSA) (2005) Contrasting Rural and Urban Fatal Crashes 1994-2003. DOT-HS-809-896. NHTSA, Washington DC. 
[6] Mueller, B.A., Rivara, F.P. and Bergman, A.B. (1988) Urban-Rural Location and the Risk of Dying in a Pedestrian-Vehicle Collision. Journal of Trauma, 28, 91-94. https://doi.org/10.1097/00005373-198801000-00013

[7] Hallmark, S.L., Peterson, E., Fitzsimmons, E., Hawkins, N., Resler, J. and Welch, T. (2007) Evaluation of Gateway and Low-Cost Traffic-Calming Treatments for Major Routes in Small Rural Communities. Center for Transportation Research and Education, Iowa State University, Ames, IA.

[8] Hallmark, S., Knickerbocker, S. and Hawkins, N. (2013) Evaluation of Low-Cost Traffic Calming for Rural Communities-Phase II. Center for Transportation Research and Education, Iowa State University, Ames, IA.

[9] Berger, W.J. and Linauer, M. (1999) Speed Reduction at City Limits by Using Raised Traffic Islands. Institute for Transportation Studies, Vienna.

[10] Martindale, A. and Urlich, C. (2010) Effectiveness of Transverse Road Markings on Reducing Vehicle Speeds. NZ Transport Agency Research Report 423.

[11] Dell'Acqua, G. (2011) Reducing Traffic Injuries Resulting from Excess Speed: Low-Cost Gateway Treatments in Italy. Journal of the Transportation Research Board, 2203, 94-99. https://doi.org/10.3141/2203-12

[12] DFT (2005) Traffic Calming on Major Roads. Department for Transport, London.

[13] Martinez, A., Mantaras, D.A. and Luque, P. (2013) Reducing Posted Speed and Perceptual Countermeasures to Improve Safety in Road Stretches with a High Concentration of Accidents. Safety Science, 60, 160-168. https://doi.org/10.1016/j.ssci.2013.07.003

[14] Allpress, J.A. and Leland Jr., L.S. (2010) Reducing Traffic Speed within Roadwork Sites Using Obtrusive Perceptual Countermeasures. Accident Analysis and Prevention, 42, 377-383. https://doi.org/10.1016/j.aap.2009.08.014

[15] Rutley, K.S. (1975) Control of Drivers' Speed by Means Other than Enforcement. Ergonomics, 18, 89-100. https://doi.org/10.1080/00140137508931443

[16] Meyer, E. (2001) A New Look at Optical Speed Bars. ITE Journal, 71, 44-48.

[17] Shinar, D. (1979) Psychology on the Road: The Human Factors in Traffic Safety. Wiley, New York.

[18] Godley, S.T., Triggs, T.J. and Fildes, B.N. (2000) Speed Reduction Mechanisms of Transverse Lines. Transportation Human Factors, 2, 297-312. https://doi.org/10.1207/STHF2-4_1

[19] Arnold, E.D. and Lantz, K.E. (2007) Evaluation of Best Practices in Traffic Operations and Safety: Phase I: Flashing LED Stop Sign and Optical Speed Bars. VTRC 07-R34. Virginia Transportation Research Council, Charlottesville.

[20] Katz, B.J. (2007) Peripheral Transverse Pavement Markings for Speed Control. Dissertation at Virginia Polytechnic Institute, Blacksburg.

[21] Latoski, S.P. (2009) Optical Speed Zone for Rural Two-Lane Highways. ITE Journal, 79, 30-35.

[22] Gates, T.J., Noyce, D.A., Talada, V. and Hill, L. (2007) The Safety and Operational Effects of "Road Diet" Conversion in Minnesota. Transportation Research Board 86th Annual Meeting, Washington DC, 12-25 January 2007, Vol. TRB\#07-1918.

[23] Corkle, J., Giese, J.L. and Marti, M.M. (2001) Investigating the Effectiveness of Traffic Calming Strategies on Driver Behavior, Traffic Flow, and Speed. Minnesota Local Road Research Board, Minnesota Department of Transportation, Saint Paul.

[24] Voigt, A.P. and Kuchangi, S.P. (2008) Evaluation of Chevron Markings on Freeway to Freeway Connector Ramps in Texas. Texas A\&M University System, Texas. 
[25] Drakapoulos, A. and Vergou, G. (2003) Evaluation of the Converging Chevron Pavement Marking Pattern in One Wisconsin Location. AAA Foundation for Traffic Safety, Washington DC.

[26] Hunter, M.P., Guin, A., Boonsiripant, S. and Rodgers, M. (2010) Evaluation of the Effectiveness of Converging Chevron Pavement Markings. FHWA-GA-10-0713. Georgia Department of Transportation, Atlanta.

[27] Ray, B., Kittelson, W., Knudsen, J., Nevers, B., Ryus, P., Sylvester, K., Potts, I., Harwood, D., Gilmore, D., Torbic, D., Hanscom, F., McGill, J. and Stewart, D. (2008) NCHRP Report 613: Guidelines for Selection of Speed Reduction Treatments at High-Speed Intersections. Transportation Research Board, Washington DC.

[28] FHWA (2012) Manual on Uniform Traffic Control Devices for Streets and Highways. 2009 Edition. Federal Highway Administration, US Department of Transportation, Washington DC. 